\title{
Effect of an acrylic resin combined with an antimicrobial polymer on biofilm formation
}

\author{
Juliê MARRA ${ }^{1}$, André Gustavo PALEARI², Larissa Santana RODRIGUEZ ${ }^{3}$, Andressa Rosa Perin LEITE4, Ana Carolina \\ PERO $^{5}$, Marco Antonio COMPAGNONI ${ }^{6}$
}

\begin{abstract}
1- DDS, MSc, PhD, Department of Prosthodontics, Paulista University - UNIP, Goiânia, GO, Brazil.
2- DDS, MSc, PhD, Department of Dental Materials and Prosthodontics, Araraquara Dental School, Univ. Estadual Paulista - UNESP, Araraquara, SP, Brazil. 3- DDS, MSc, PhD student, Department of Dental Materials and Prosthodontics, Araraquara Dental School, Univ. Estadual Paulista - UNESP, Araraquara, $\mathrm{SP}$, Brazil.

4- DDS, MSc student, Department of Dental Materials and Prosthodontics, Araraquara Dental School, Univ. Estadual Paulista - UNESP, Araraquara, SP, Brazil. 5- DDS, MSc, PhD, Assistant Professor, Department of Dental Materials and Prosthodontics, Araraquara Dental School, Univ. Estadual Paulista - UNESP, Araraquara, SP, Brazil.

6- DDS, MSc, PhD, Full Professor, Department of Dental Materials and Prosthodontics, Araraquara Dental School, Univ. Estadual Paulista - UNESP, Araraquara, SP, Brazil.
\end{abstract}

Corresponding address: Dr. Marco Antonio Compagnoni - Departamento de Materiais Odontológicos e Prótese - Faculdade de Odontologia de Araraquara - UNESP - Rua Humaitá, 1680 - 14801-903 - Araraquara - SP - Brazil - Phone/Fax: +55 1633016411 +55 16 33016406 - e-mail: compagno@foar.unesp.br

Received: May 16, 2012 - Modification: August 23, 2012 - Accepted: September 17, 2012

\section{ABSTRACT}

$\mathrm{O}$ bjectives: The purpose of this study was to evaluate the antimicrobial activity of an acrylic resin combined with an antimicrobial polymer poly (2-tert-butylaminoethyl) methacrylate (PTBAEMA) to inhibit Staphylococcus aureus, Streptococcus mutans and Candida albicans biofilm formation. Material and Methods: Discs of a heat-polymerized acrylic resin were produced and divided according to PTBAEMA concentration: 0 (control), 10 and $25 \%$. The specimens were inoculated $\left(10^{7} \mathrm{CFU} / \mathrm{mL}\right)$ and incubated at $37^{\circ} \mathrm{C}$ for 48 h. After incubation, the wells were washed and each specimen was sonicated for $20 \mathrm{~min}$. Replicate aliquots of resultant suspensions were plated at dilutions at $37^{\circ} \mathrm{C}$ for $48 \mathrm{~h}$. The number of colony-forming units (CFU) was counted and expressed as log (CFU+1)/mL and analyzed statistically with $\alpha=.05$. Results: The results showed that $25 \%$ PTBAEMA completely inhibited $S$. aureus and $S$. mutans biofilm formation. A significant reduction of $\log (\mathrm{CFU}+1) / \mathrm{mL}$ in count of $S$. aureus (control: $7.9 \pm 0.8 \mathrm{~A} ; 10 \%: 3.8 \pm 3.3 \mathrm{~B}$ ) and $\mathrm{S}$. mutans (control: $7.5 \pm 0.7 \mathrm{~A} ; 10 \%$ : $5.1 \pm 2.7 \mathrm{~B}$ ) was observed for the group containing $10 \%$ PTBAEMA (Mann-Whitney, $\mathrm{p}<0.05)$. For $C$. albicans, differences were not significant among the groups (control: $6.6 \pm 0.2 \mathrm{~A} ; 10 \%$ : $6.6 \pm 0.4 \mathrm{~A} ; 25 \%$ : $6.4 \pm 0.1 \mathrm{~A}$ ), (Kruskal-Wallis, $p>0.05, \mathrm{P}=0.079$ ). Conclusions: Acrylic resin combined with 10 and 25\% of PTBAEMA showed significant antimicrobial activity against $S$. aureus and $S$. mutans biofilm, but it was inactive against the C. albicans biofilm.

Key words: Acrylic resins. Biofilms. Polymers. Dental materials.

\section{INTRODUCTION}

Acrylic resins are commonly used for denture fabrication since they exhibit adequate physical, mechanical, and esthetic properties ${ }^{1}$. However, it has been shown that denture base acrylic resins may act as reservoirs for microorganisms and have the potential to support biofilm formation ${ }^{21,23}$. Microbial growth on the denture surface results from the adherence of microbial cells enhanced by surface roughness, and from adhesive interactions between Candida species and oral bacteria ${ }^{16,30}$. Several studies have demonstrated an association between C. albicans or other species of Candida, and several oral bacteria such as Streptococcus sanguis, Streptococcus salivarius, Streptococcus mutans, Fusobacterium nucleatum and Actinomyces $v_{i s c o s} s^{12,18}$. They can induce a chronic inflammatory response in the oral mucosa, described as denture stomatitis, which is the most common infectious 
disease affecting the oral mucosa and is highly prevalent in denture wearers ${ }^{2,15}$. C. albicans and Staphylococcus aureus have also been associated with lesions in several patients with angular cheilitis, as these microorganisms show a high ability to adhere to oral tissues ${ }^{1}$.

To avoid the formation of biofilm on denture base resin surfaces, several attempts to incorporate antifungal agents or antiseptics into tissue conditioners and denture acrylic resins have been

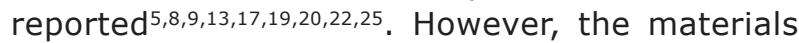
exhibited antimicrobial activity by releasing antimicrobial agents that could have toxic effects on the oral mucosa, damage the mechanical properties of the materials, and lose their effectiveness over time ${ }^{11,22}$.

A possible alternative to solve this problem could be to substitute these substances with macromolecular antimicrobial agents, such as polycationic polymers with the advantages of reduced toxicity and not causing bacterial resistance ${ }^{24}$. Poly(2-tert-butylaminoethyl) methacrylate (PTBAEMA) is a functionalized polycationic polymer with pendant amino groups that acts as a very efficient contact biocide. It also has low solubility in water, which makes this biocide especially useful for incorporation into materials designed to be in contact with water, since one can expect very low leachability of PTBAEMA from polymer blends and compounds ${ }^{14}$. This polymer has been incorporated into a polyethylene with potential fields of application, such as water treatment and inclusion in medical devices ${ }^{24}$.

The aim of this study was to evaluate the effect of a denture based acrylic resin containing different percentages of the polymer poly(2-tertbutylaminoethyl) methacrylate against the biofilm, in vitro, of Staphylococcus aureus, Streptococcus mutans and Candida albicans. The null hypothesis was that denture based acrylic resin containing different percentages of the polymer poly (2-tertbutylaminoethyl) methacrylate would not inhibit the formation of Staphylococcus aureus, Streptococcus mutans and Candida albicans biofilms.

\section{MATERIAL AND METHODS}

Poly(2-tert-butylaminoethyl) methacrylate
synthesis
Poly(2-tert-butylaminoethyl) methacrylate
(PTBAEMA) is an antimicrobial polymer in powder form. Previously to incorporation in acrylic resin it was necessary to solubilize the commercially available monomer, 2-tert-butylaminoethyl methacrylate (Evonik Degussa Brasil Ltda, São Paulo, SP, Brazil). The synthesis was performed as described by Sosna, et al. ${ }^{26}$ (2004). First a threenecked flask was charged with $90 \mathrm{ml}$ of 2-tertbutylaminoethyl and $180 \mathrm{~mL}$ of ethanol and heated to $65^{\circ} \mathrm{C}$ under a stream of argon. Next, $0.745 \mathrm{~g}$ of azobisisobutyronitrile (Sigma-Aldrich, St Louis, MO, USA) dissolved in $20 \mathrm{ml}$ of ethyl methyl ketone was slowly added drop-wise, with stirring. The mixture was heated to $70^{\circ} \mathrm{C}$ and stirred at this temperature for $72 \mathrm{~h}$. After this time had elapsed, the reaction mixture was stirred into $1 \mathrm{~L}$ of demineralized water, whereupon the polymeric product was precipitated. After the product was separated by filtration, the filter residue was washed with $100 \mathrm{~mL}$ of a $10 \%$ solution of ethanol in water in order to remove any residual monomers still present. The product was dried under vacuum at $50^{\circ} \mathrm{C}$ and then ground.

\section{Specimen fabrication}

Initially, a metal mold was used to make diskshaped silicone patterns (Zetaplus, IndurentZhermack, Badia Polesine, Rovigo, Italy) measuring $15 \mathrm{~mm} \times 2 \mathrm{~mm}$. These silicone patterns were sandwiched between two glass slides and invested in flasks with type IV dental stone (Herodent, Vigodent SA Ind. Com., Rio de Janeiro, RJ, Brazil). After the dental stone had set, the flasks were separated and the silicone patterns were removed, leaving disk-shaped cavities.

Specimens were divided into three groups $(n=10)$ according to Table 1 . The polymer PTBAEMA was mixed with the acrylic resin powder (Lucitone 550, Dentsply Indústria e Comércio Ltda, Petrópolis, $\mathrm{RJ}$, Brazil) at concentrations: 0\% (control), 10\% and $25 \%$. The combined powder was then mixed with the resin liquid and the resin dough was put into the disk-shaped cavities. The resin was polymerized according to the manufacturer's recommendations. After polymerization, the excess material was carefully removed using a bur (Maxicut; Maillefer SA, Ballaigues, Switzerland). After this, the specimens were sterilized using ethylene oxide gas, with a temperature of $50^{\circ} \mathrm{C} \pm 5^{\circ} \mathrm{C}$ for 4 hours.

Microorganisms and microbial suspension

Table 1- Groups according to the percentage of poly(2-tert-butylaminoethyl) methacrylate (PTBAEMA)

\begin{tabular}{cccc}
\hline Percentage of PTBAEMA (\%) & Powder resin $(\mathbf{g})$ & PTBAEMA $(\mathbf{g})$ & Liquid resin $(\mathbf{m L})$ \\
\hline 0 & 21 & - & 10 \\
10 & 21 & 2.1 & 11 \\
25 & 21 & 5.25 & 12.5 \\
\hline
\end{tabular}


In order to assay the antimicrobial activity of the experimental specimens, three standard strain microorganisms were tested: Staphylococcus aureus ATCC 25923, Streptococcus mutans ATCC 25175 and Candida albicans ATCC 90028 . Microbial suspensions were obtained from single colonies isolated on agar plates, inoculated in the appropriate broth for overnight cultures at $37^{\circ} \mathrm{C}$. S. mutans was grown in brain-heart infusion (BHI) broth and $C$. albicans and $S$. aureus strains were grown in tryptic soy broth (TSB). Cells of the resultant cultures were harvested, washed twice with phosphate-buffered saline (PBS, pH 7.2), centrifuged at 5000x g for 5 min and re-suspended in appropriate fresh broth. Microbial suspensions were spectrophotometrically (BioPhotometer plus, Eppendorf, Hauppauge, NY, United States) standardized to a concentration of $1 \times 10^{7}$ cells $/ \mathrm{mL}$.

\section{Biofilm development}

Biofilms of each microorganism (Staphylococcus aureus, Streptococcus mutans and Candida albicans) were produced in pre-sterilized, 12-well polystyrene flat-bottomed microtiter plates ${ }^{27}$. First each sterile acrylic resin specimen was individually placed in each well of a microtiter plate and 2 $\mathrm{mL}$ of standard cell suspensions ( $10^{7}$ cells $/ \mathrm{mL}$ ) prepared as mentioned above and added to each well containing a specimen. The plate was incubated for $90 \mathrm{~min}$ at $37^{\circ} \mathrm{C}$ in an orbital shaker at $75 \mathrm{rpm}$ to promote microorganism adherence to the specimen surfaces (adhesion phase). After the adhesion phase, the specimens were transferred to new wells and the non-adherent cells were removed from the specimen by gently washing twice with $2 \mathrm{~mL}$ PBS. To promote biofilm growth (biofilm phase), 2 $\mathrm{mL}$ of appropriate fresh broth was added to each well. The plates were covered and incubated at $37^{\circ} \mathrm{C}$ at $75 \mathrm{rpm}$ for $48 \mathrm{~h}$ under aerobic conditions (Staphylococcus aureus and Candida albicans) and anaerobic conditions (Streptococcus mutans). After incubation, the plates were removed from the incubator and the wells gently washed twice with PBS. After washing, the specimens were transferred to a tube containing distilled water and sonicated for 20 min to disrupt the biofilm cell aggregates. The resultant suspension containing the detached biofilm cells was vortexed, diluted and plated onto sterile Petri dishes containing selective media for Staphylococcus aureus, Streptococcus mutans and Candida albicans for $48 \mathrm{~h}$ at $37^{\circ} \mathrm{C}$ under aerobic or anaerobic conditions, as deemed appropriate. The media used for plating S. mutans was SB20, for $C$. albicans Sabouraud Dextrose Agar was used with $5 \mu \mathrm{g} / \mathrm{mL}$ chloranphenicol and S. aureus strains were grown in Mannitol Salt Agar. Staphylococcus aureus and Candida albicans were cultivated under aerobic conditions and Streptococcus mutans under anaerobic conditions. After incubation, colony counts of each Petri dish were quantified using a digital colony counter (CP 600 Plus, Phoenix Ind. Com. Equipamentos Científicos Ltda, Araraquara, SP, Brazil).

The microbial count data obtained were expressed as log $(\mathrm{CFU}+1) / \mathrm{mL}$. No homogeneity of variances was observed for the three species evaluated (Levene test, $P<0.05$ ), and nonparametric tests were then performed. S. aureus and $S$. mutans counts were compared by the Mann-Whitney test and C. albicans results were compared by the Kruskal-Wallis test. All analyses were performed with $\alpha=.05$.

\section{RESULTS}

The number of viable cells of each microorganism and standard deviations are presented in Figures 1,2 and 3.

A strong dose-dependent bactericidal effect against Staphylococcus aureus and Streptococcus mutans biofilms was observed with a reduction in viable cells according to the percentage of PTBAEMA incorporated into the acrylic resin. For these microorganisms, significant antimicrobial activity was observed for the acrylic resin containing $10 \%$ PTBAEMA in comparison with the corresponding control groups $(p<0.05)$. A decrease in the number of viable biofilm cells of $S$. aureus (control group: $7.9 \pm 0.8^{\mathrm{A}}$; group $10 \%: 3.8 \pm 3.3^{\mathrm{B}}$ ) and S. mutans (control group: $7.5 \pm 0.7^{A}$; group $10 \%$ : $5.1 \pm 2.7^{B}$ ) was demonstrated during contact with the acrylic resin specimens containing 10\% PTBAEMA. In addition, the number of viable biofilm cells of $S$. aureus and $S$. mutans was strongly reduced during contact with the acrylic resin specimens containing $25 \%$ PTBAEMA, reducing the number of cells to zero. However, for the $C$. albicans biofilm (control group: $6.6 \pm 0.2^{A}$; group $10 \%$ : $\left.6.6 \pm 0.4^{A}, 6.4 \pm 0.1^{A}\right)$,

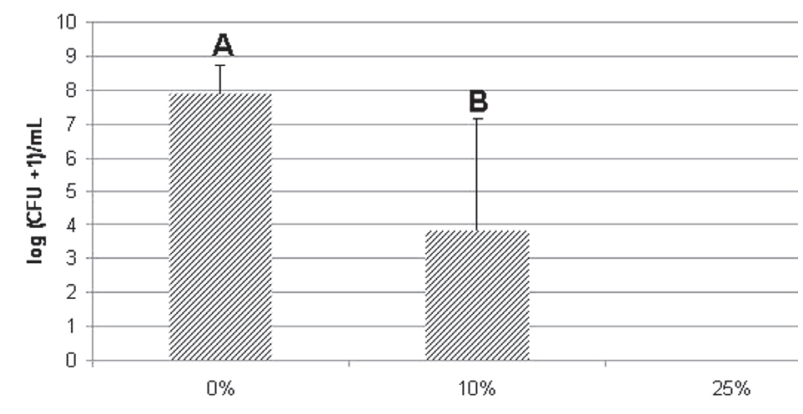

Figure 1- Effect of different percentages of poly(2-tertbutylaminoethyl) methacrylate (PTBAEMA) incorporated into acrylic resin specimens on the viability of Staphylococcus aureus biofilm cells. Error bars represent standard deviations $(\alpha=0.05)$. Different capital letters denote significant differences among groups (MannWhitney test, $p=0.001$ ) 


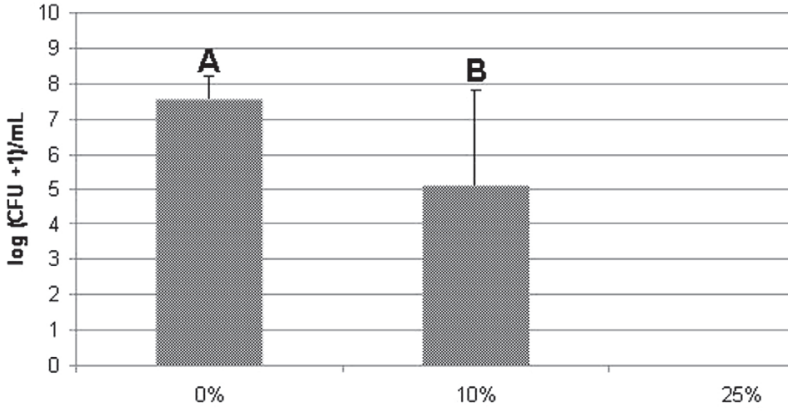

Figure 2 - Effect of different percentages of poly(2-tertbutylaminoethyl) methacrylate (PTBAEMA) incorporated into acrylic resin specimens on the viability of Streptococcus mutans biofilm cells. Error bars represent standard deviations $(\alpha=0.05)$. Different capital letters denote significant differences among groups (MannWhitney test, $p=0.001$ )

there was no significant difference among the groups $(p>0.05)$.

\section{DISCUSSION}

In this study, a water-insoluble polycationic polymer poly (2-tert-butylaminoethyl) methacrylate (PTBAEMA) was incorporated into an acrylic resin, whose biocidal properties resulted from the pendant bulky secondary amine of the methacrylate backbone ${ }^{14}$.

The findings of this study showed that the group containing $10 \%$ PTBAEMA significantly reduced the number of $S$. aureus and $S$. mutans biofilms formed on the specimen surfaces when compared with the control group. In the group containing 25\% PTBAEMA, complete inhibition of $S$. aureus and $S$. mutans biofilm formation was observed. These results show a dose-dependent response to PTBAEMA and were similar to results of others authors. Seyfriedsberger, et al.24 (2006) investigated the antimicrobial properties of a polyethylene containing different concentrations of PTBAEMA, which reduced the number of CFU/ $\mathrm{mL}$ of $S$. aureus to zero after 24 hours of contact with groups containing PTBAEMA. The findings of Ignatova, et al. ${ }^{10}$ (2006) showed that a stainless steel coated PTBAEMA reduced the adhesion of S. aureus by $99.9 \%$. Similar findings were also reported by Lenoir, et al. ${ }^{14}$ (2006) and Thomassin, et al. ${ }^{28}$ (2007) after evaluation of the antimicrobial properties against $E$. coli, of compounds into which PTBAEMA had been incorporated, showing that the bacteria had been completely eliminated after a certain period of time.

Although this study did not evaluate mixed species biofilm, it is known that bacteria can significantly influence and modify candidal growth and biofilm formation ${ }^{3}$. This study presented a significant effect of PTBAEMA against the $S$. mutans

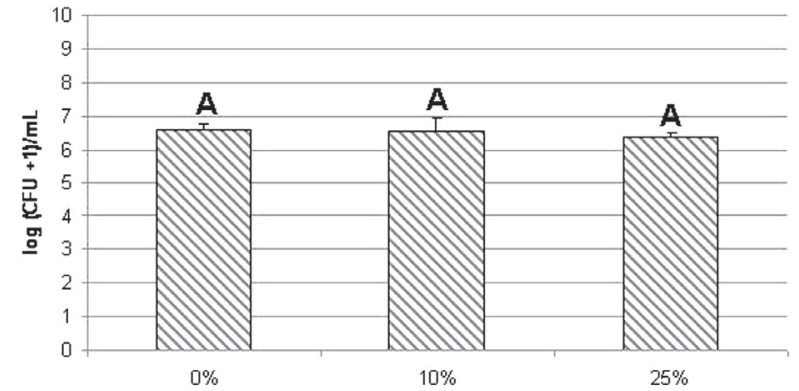

Figure 3 - Effect of different percentages of poly(2-tertbutylaminoethyl) methacrylate (PTBAEMA) incorporated into acrylic resin specimens on the viability of Candida albicans biofilm cells. Error bars represent standard deviations $(\alpha=0.05)$. Identical capital letters denote no significant differences among groups (Kruskal-Wallis test, $p=0.079$ )

biofilm, which is considered one of the primary colonizers of oral biofilm, and is heavily involved in the initial stages of biofilm formation, producing extra cellular matrix polysaccharide and facilitating the attachment of other microorganisms such as $C$. albicans ${ }^{14}$. Moreover, the reduction in the amount of S. aureus biofilm observed in this study represents a significant result, since $S$. aureus is a normal colonizer of the oral cavity, and this colonization can be a potential danger to the patient as a source of bacterial dissemination to other sites in the body, and a source of transmission to other people, food or objects ${ }^{3}$.

According to Lenoir, et al. ${ }^{14}$ (2008) the biocidal action is based on the interaction between the membrane of the bacteria in contact with PTBAEMA. The divalent cations $\mathrm{Ca}^{2+}$ and/or $\mathrm{Mg}^{2+}$ that crossbridge the outer membrane of the bacteria are replaced by the charged amine groups of PTBAEMA, followed by membrane disorganization and cell lyses. Moreover, PTBAEMA can also act in inducing a phase-separation of charged and uncharged lipids inside the cytoplasma membrane of bacteria. Finally, the cytoplasma membrane disintegrates, which causes the death of the microorganism (apoptosis) ${ }^{24}$.

The results of this study also demonstrated that the denture base acrylic resin with incorporation of PTBAEMA did not have antifungal activity against Candida albicans. Park, et al. ${ }^{20}$ (2008) incorporated methacrylic acid into an acrylic denture base resin and observed a reduction in the number of $C$. albicans. These conflicting results may be related to the ability of each agent to interact with the cell wall of $C$. albicans, much like other living cells, has a net negative surface charge, providing an environment of electrostatic repulsion through the negativenegative charge interactions with the polymer ${ }^{22}$. Similarly, Wady, et al. ${ }^{29}$ (2012) incorporated silver nanoparticles (AgNPs) into a denture base acrylic 
resin and did not observed an effect on C. albicans adherence and biofilm formation.

The effect of PTBAEMA incorporated to denture base acrylic resins against $C$. albicans is not well-established, since the biocide power of this agent has been evaluated only in polyethylene compounds $10,14,24,28$. The fungus, different from the bacteria, shows a cell wall composed of approximately 80 to $90 \%$ carbohydrate. Moreover, the microfibrillar polymers (b-glucans and chitin) represent the structural components of the wall. They form a rigid skeleton that provides strong physical properties to the cell ${ }^{6}$. Consequently, it might be supposed that this rigid skeleton protects C. albicans against PTBAEMA and do not allow the antimicrobial agent to displace $\mathrm{Ca}^{2+}$ and/ or $\mathrm{Mg}^{2+}$ ions from the outer wall of the cell.

Further studies should be conducted to determine the cytotoxicity of this polymer and to assess possible changes in the properties of acrylic resin due to the incorporation of PTBAEMA, such as flexural strength, surface roughness, Vickers hardness and color stability of acrylic resin. According to previous studies $5,8,20,25$ that have incorporated antimicrobials agents into acrylic resin, some kind of damage on the mechanical and/or physical properties of the acrylic resin are expected. The characterization of the acrylic resin after the incorporation of PTBAEMA is not described in this study, since chemical and mechanical tests are being conducted and will be showed in a specific paper on this subject.

Within the limitations of this study, favorable outcomes were detected indicating that PTBAEMA might also be successfully associated with other dental materials since Streptococcus $s p$. are considered a fundamental building block of the initial oral biofilms ${ }^{7}$. In addition, Staphylococcal infections, particularly those caused by Staphylococcus aureus, produce substantial morbidity and mortality in hemodialysis patients ${ }^{4}$.

\section{CONCLUSION}

Within the limitations of this study, it can be concluded that the denture base acrylic resin combined with $10 \%$ and $25 \%$ PTBAEMA showed a significant antimicrobial activity against $S$. aureus and S. mutans biofilm, but had no significant effect on the $C$. albicans biofilm formation.

\section{ACKNOWLEDGEMENTS}

The authors would like to thank Professor Adhemar C. Ruvollo-Filho, of the Federal University of São Carlos (UFSCar) for his assistance with the synthesis of poly(2-tert-butylaminoethyl) methacrylate; Professor Raphael Freitas de Souza of Ribeirão Preto Dental School - University of São
Paulo (USP) for his assistance with the statistical analysis; Evonik-Degussa (São Paulo, Brazil) for supplying a research sample of TBAEMA and FAPESP for financial support (Grants No. 2008/02602-0 and No. 2007/04061-3).

\section{REFERENCES}

1- Aguirre JM, Verdugo F, Zamacona JM, Quindos G, Ponton J. Cytological changes in oral mucosa in denture stomatitis. Gerodontology. 1996;13:63-7.

2- Arendorf TM, Walker DM. Denture stomatitis: a review. J Oral Rehabil. 1987;14:217-27.

3- Baena-Monroy T, Moreno-Maldonado V, Franco-Martínez F, Aldape-Barrios B, Quindós G, Sánchez-Vargas LO. Candida albicans, Staphylococcus aureus and Streptococcus mutans colonization in patients wearing dental prosthesis. Med Oral Patol Oral Cir Bucal. 2005;10(Suppl 1):E27-39.

4- Balaban N, Gov Y, Bitler A, Boelaert R. Prevention of Staphylococcus aureus biofilm on dialysis catheters and adherence to human cells. Kidney Int. 2003;63:340-5.

5- Casemiro LA, Gomes Martins CH, Pires-de-Souza FC, Panzeri $\mathrm{H}$. Antimicrobial and mechanical properties of acrylic resins with incorporated silver-zinc zeolite - part I. Gerodontology. 2008;25:187-94.

6- Chaffin WL, López-Ribot JL, Casanova M, Gozalbo D, Martínez JP. Cell wall and secreted proteins of Candida albicans: identification, function, and expression. Microbiol Mol Biol Rev. 1998;62:130-80. 7- Chalmers NI, Palmer RJ Jr, Cisar JO, Kolenbrander PE. Characterization of a Streptococcus $s p$.-Veillonella $s p$. community micro-manipulated from dental plaque. J Bacteriol. 2008;190:814554.

8- Cunha TR, Regis RR, Bonatti MR, Souza RF. Influence of incorporation of fluoroalkyl methacrylates on roughness and flexural strength of a denture base acrylic resin. J Appl Oral Sci. 2009;17:103-7.

9- Dhir G, Berzins DW, Dhuru VB, Periathamby AR, Dentino A. Physical properties of denture base resins potentially resistant to Candida adhesion. J Prosthodont. 2007;16:465-72.

10- Ignatova M, Voccia S, Gilbert B, Markova N, Cossement $D$, Gouttebaron R, et al. Combination of electrografting and atom-transfer radical polymerization for making the stainless steel surface antibacterial and protein anti-adhesive. Langmuir. $2006 ; 22: 255-62$.

11- Imazato S, Kinomoto Y, Tarumi H, Ebisu S, Tay FR. Antibacterial activity and bonding characteristics of an adhesive resin containing antibacterial monomer MDPB. Dent Mater. 2003;19:313-9.

12- Jabra-Rizk MA, Falkler WA Jr, Merz WG, Baqui AA, Kelley JI, Meiller TF. Cell surface hydrophobicity associated adherence of Candida dubliniensis to human buccal epithelial cells. Rev Iberoam Micol. 2001;18:17-22.

13- Kuroki K, Hayashi T, Sato K, Asai T, Okano M, Kominami Y, et al. Effect of self-cured acrylic resin added with an inorganic antibacterial agent on Streptococcus mutans. Dent Mater J. 2010;29:277-85.

14- Lenoir $S$, Pagnoulle $C$, Galleni $M$, Compère $P$, Jérôme $R$, Detrembleur $C$. Polyolefin matrixes with permanent antibacterial activity: preparation, antibacterial activity, and action mode of the active species. Biomacromolecules. 2006;7:2291-6.

$15-$ Moskona D, Kaplan I. Oral lesions in elderly denture wearers. Clin Prev Dent. 1992;14:11-4.

16- Nair RG, Samaranayake LP. The effect of oral commensal bacteria on candidal adhesion to denture acrylic surfaces. An in vitro study. APMIS. 1996;104:339-49.

17- Nikawa $H$, Egusa $H$, Makihira S, Yamashiro $H$, Fukushima $H$, Jin $\mathrm{C}$, et al. Alteration of the co-adherence of Candida albicans with oral bacteria by dietary sugars. Oral Microbiol Immunol. 2001; 16:279-83. 
18- Nikawa H, Yamamoto T, Hamada T, Rahardjo MB, Murata $\mathrm{H}$, Nakanoda $\mathrm{S}$, et al. Antifungal effect of zeolite-incorporated tissue conditioner against Candida albicans growth and/or acid production. J Oral Rehabil. 1997;24:350-7.

19- Paleari AG, Marra J, Pero AC, Rodriguez LS, Ruvolo-Filho A, Compagnoni MA. Effect of incorporation of 2-tert-butylaminoethyl methacrylate on flexural strength of a denture base acrylic resin. J Appl Oral Sci. 2011;19:195-9.

20- Park SE, Blissett R, Susarla SM, Weber HP. Candida albicans adherence to surface-modified denture resin surfaces. J Prosthodont. 2008;17:365-9.

21- Pereira-Cenci T, Del Bel Cury AA, Crielaard W, Ten Cate JM. Development of Candida-associated denture stomatitis: new insights. J Appl Oral Sci. 2008;16:86-94.

22- Pesci-Bardon C, Fosse T, Serre D, Madinier I. In vitro antiseptic properties of an ammonium compound combined with denture base acrylic resin. Gerodontology. 2006;23:111-6.

23- Radford DR, Sweet SP, Challacombe SJ, Walter JD. Adherence of Candida albicans to denture-base materials with different surface finishes. J Dent. 1998;26:577-83.

24- Seyfriedsberger G, Rametsteiner K, Kern W. Polyethylene compounds with antimicrobial surface properties. Euro Polym J. 2006;42:3383-9.
25- Shibata T, Hamada N, Kimoto K, Sawada T, Sawada T, Kumada $H$, et al. Antifungal effect of acrylic resin containing apatite-coated $\mathrm{TiO}_{2}$ photocatalist. Dent Mater J. 2007;26:437-44.

26- Sosna F, Ottersbach P, Kossmann B, inventors; CREAVIS Tech \& Innovation $\mathrm{GMBH}$, depositor. Antimicrobial additives. US Patent 6790910 B1. 14 Sep. 2004.

27- Thein ZM, Samaranayake YH, Samaranayake LP. In vitro biofilm formation of Candida albicans and non-albicans Candida species under dynamic and anaerobic conditions. Arch Oral Biol. 2007;52:761-7.

28- Thomassin JM, Lenoir S, Riga J, Jérôme R, Detrembleur C. Grafting of poly[2-(tert-butylamino)ethyl methacrylate] onto polypropylene by reactive blending and antibacterial activity of the copolymer. Biomacromolecules. 2007;8:1171-7.

29- Wady AF, Machado AL, Zucolotto V, Zamperini CA, Berni E, Vergani CE. Evaluation of Candida albicans adhesion and biofilm formation on a denture base acrylic resin containing silver nanoparticles. J Appl Microbiol. 2012;112:1163-72.

30- Zamperini CA, Machado AL, Vergani CE, Pavarina AC, Giampaolo ET, Cruz NC. Adherence in vitro of Candida albicans to plasma treated acrylic resin. Effect of plasma parameters, surface roughness and salivary pellicle. Arch Oral Biol. 2010;55:763-70. 